\title{
Uranium in agricultural soils and drinking water wells on the Swiss Plateau
}

\author{
Moritz Bigalke ${ }^{a^{*}}$, Lorenz Schwab ${ }^{a}$, Agnes Rehmus ${ }^{a}$, Patrik Tondo ${ }^{b}$, Markus Flisch ${ }^{b}$
} $s^{2}$

\author{
${ }^{a}$ Institute of Geography, University of Bern, Hallerstr. 12, 3012 Bern, Switzerland

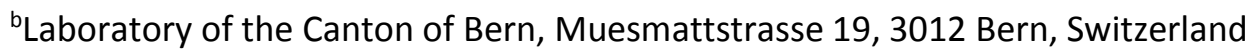 \\ *Corresponding author: Moritz Bigalke; moritz.bigalke@giub.unibe.ch; +41(0)316314055
}

\section{Abstract}

Mineral phosphorus fertilizers are regularly applied to agricultural sites, but their uranium (U)

content is potentially hazardous to humans and the environment. Fertilizer-derived $U$ can

accumulate in the soil, but might also leach to ground-, spring and surface waters. We

sampled 19 mineral fertilizers from the canton of Bern and soils of three arable and one

forest reference sites at each of four locations with elevated $U$ concentrations $\left(7-28 \mu \mathrm{g} \mathrm{L}^{-1}\right)$

in nearby drinking water wells. The total $U$ concentrations of the fertilizers were measured.

The soils were analysed at three depth intervals down to $1 \mathrm{~m}$ for general soil parameters,

total $\mathrm{Cd}, \mathrm{P}, \mathrm{U}$ and $\mathrm{NaHCO}_{3}$-extractable $\mathrm{U}$ concentrations, and ${ }^{234 / 238} \mathrm{U}$ activity ratios (AR). The $U$ concentrations and AR values of the drinking water samples were also measured. A theoretical assessment showed that fertilizer-derived $U$ may cause high $U$ concentrations in leaching waters (up to approx. $25 \mathrm{\mu g} \mathrm{L}^{-1}$ ), but normally contributes only a small amount (approx. 0-3 $\mu \mathrm{g} \mathrm{L}^{-1}$ ). The arable soils investigated showed no significant $\mathrm{U}$ accumulation compared to the forest sites. The close positive correlation of $\mathrm{AR}$ with $\mathrm{NaHCO}_{3}$-extractable $\mathrm{U}$ $(R=0.7, p<0.001)$ indicates that application of fertilizer can increase the extractable $U$ pool. The lack of depth gradients in the soil $U$ concentrations $\left(1.5-2.7 \mathrm{mg} \mathrm{kg}^{-1}\right)$ and $A R(0.90-1.06)$ ratios are inconsistent with the accumulation of $U$ in the surface soil, and might indicate some leaching of fertilizer-derived $U$. The AR values in the water samples were close to 1 , possibly suggesting an influence of fertilizer-derived $U$. However, based on findings from the literature and considering the heterogeneity of the catchment area, the agricultural practices, and the 
comparatively long distance to the groundwater, we conclude that fertilizer-derived $U$ makes only a minor contribution to the elevated $U$ concentrations in the water samples.

Keywords: Uranium, mineral fertilizer, soil, water, activity ratio

Capsule: Mineral fertilizer application causes an increase of $\mathrm{NaHCO}_{3}$-extractable $\mathrm{U}$ in soil, and might significantly contribute to $U$ concentrations in waters at background levels, but is probably only a minor contributor at high $U$ concentrations in the waters of the Swiss Plateau.

\section{Highlights:}

- $\quad$ Mineral P fertilizers contain high $U$ concentrations.

- Mineral fertilization could cause high $U$ concentrations in waters.

- The concentration of extractable $U$ is linked to mineral fertilizer application.

- No accumulation in the surface soil might indicate partial leaching of $U$.

- Fertilizer-derived $U$ is probably only of minor importance for water concentrations.

\section{Graphical Abstract}
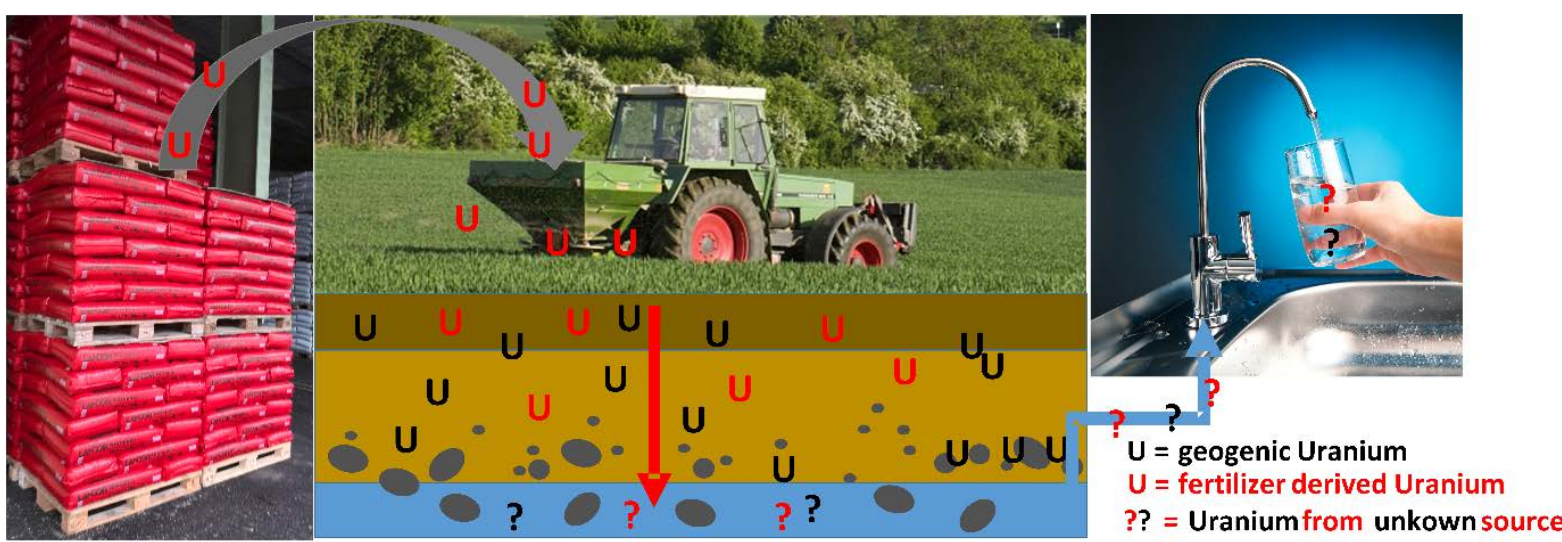

?? = Uranium from unkown source 


\section{Introduction}

Mineral based phosphorous fertilizers are regularly applied to many agricultural sites, but often contain high concentrations of $U$. Depending on the soil conditions, fertilizer-derived $U$ might be mobile and contaminate ground- and surface waters (Birke and Rauch, 2008; Huhle et al., 2008; Schnug and Lottermoser, 2013). Finally, the $U$ may end up in drinking water, which is the major source for human uptake of toxic $U$ (65\%-95\% of total $U$ uptake; Schnug, 2012). Mineral based phosphorous fertilizers are produced from phosphate rocks of igneous or sedimentary origin. Depending on the source, sedimentary phosphorites are heavily enriched in $\mathrm{U}$ (up to $280 \mathrm{mg} \mathrm{kg}^{-1}$; McLaughlin et al., 1996). During the process of fertilizer production, $\mathrm{U}$ is enriched in the fertilizers by up to $150 \%$ (Sattouf, 2007). Thus, different types of fertilizers (e.g. triple superphosphate and diammoniumphosphate) may have very different $U$ contents (Table S1) depending on the source and type of production. When mineral based fertilizers are applied to soil, they are rapidly solubilized and the mobilized $U$ can be sorbed to soil components, precipitated, or leached. Uranium binds to organic matter, Al and Fe oxides, clay minerals and soil organisms (Echevarria et al., 2001; Zheng et al., 2003; Zielinski et al., 2000). For soils with high clay and organic-matter content, $U$ is anticipated not to migrate substantially (Rogasik et al., 2008). Accordingly, several studies have shown that long-term fertilization with mineral based P-fertilizers leads to substantial accumulation of $U$ in soils, particularly topsoil, compared to unfertilized soils (Bigalke et al., 2017; Jones, 1992; Rogasik et al., 2008; Schipper et al., 2011; Takeda et al., 2005, 2006; Taylor, 2007; Wetterlind et al., 2012; Yamaguchi et al., 2009; Zielinski et al., 2006). In accordance with these findings, a number of authors have pointed to regional variations in concentrations of $U$ in drinking water generally related to bedrock composition, even if the direct relationship might be complicated by groundwater flow through different rock formations (CCME, 2011; Stalder et al., 2012). However, a number of studies also found indications of $U$ transfer from fertilizers to water bodies (Azouazi et al., 2001; Barisic et al., 1992; Conceicao and Bonotto, 2003; Huhle et al., 2008; Smidt et al., 2012; Zielinski et al., 2000). The influence of fertilizer-derived $U$ inputs can be tested by comparing fertilized and unfertilized reference sites (Birke and Rauch, 2008; Huhle et al., 2008; Rogasik 
et al., 2008) or from correlations between $U$ and other fertilizer-derived components such as nitrate, $\mathrm{K}$ and $\mathrm{B}$, especially in shallow drinking waters at agricultural sites (Knolle, 2008; Popit et al., 2004; Schäf et al., 2007; Smidt et al., 2012).

One important reason for the different findings in terms fertilizer $U$ transfer to groundwaters is the $U$ mobility in soils. The $\mathrm{pH}$ is one of the most important drivers of $U$ mobility in soils (Echevarria et al., 2001; Tylor and Olsson, 2001). The lowest mobility of $U$ is around pH 7 but mobility increases with decreasing $\mathrm{pH}$ because of decreasing number of binding sites and changes in $U$ speciation. Depending on $\mathrm{pH}$ and the presence of organic and inorganic ligands such as phosphates $\left(\mathrm{PO}_{4}{ }^{3-}\right)$, carbonates $\left(\mathrm{CO}_{3}{ }^{2-}\right)$, sulphates $\left(\mathrm{SO}_{4}{ }^{2-}\right)$, chlorides $\left(\mathrm{Cl}^{-}\right)$or fluorides $\left(F^{-}\right) \cup$ forms stable complexes of different mobilities (Bourdon et al., 2003; Vandenhove et al., 2007). Especially under slightly alkaline and oxic conditions -as they are common in many Swiss agricultural fields- $U$ is therefore quite mobile (Jacques et al., 2006). The presence of carbonates particularly increases the mobility of $U$ in alkaline soils because $U$-carbonate complexes are predominantly neutral or negatively charged and have a low affinity for soil minerals (Echevarria et al., 2001; Read et al., 2008; Zheng et al., 2003). Besides pH and complexing agents the amount of possible binding sites (organic material, Fe oxides and clay) controls the possible $U$ sorption (Rogasik et al., 2008). Depending on soil properties, $U$ does or does not significantly accumulate in soils but is readily transferred to aquifers (Hamamo et al., 1995; Mortvedt, 1994), especially if the ground water table is close to the soil surface (Huhle et al., 2008) .

The ${ }^{234} \mathrm{U} /{ }^{238} \mathrm{U}$ alpha activity ratio (AR) is a tool to relate $\mathrm{U}$ to its source directly. In an undisturbed closed system, as is assumed in a phosphate rock deposit, a secular equilibrium becomes established and AR levels approach 1 (Figure 1; Bourdon et al., 2003; Keith et al., 2007). Conversely, recoil processes and the spontaneous oxidation of $\mathrm{U}^{4+}$ to $\mathrm{U}^{6+}$ during decay are reasons for preferential leaching of ${ }^{234} \mathrm{U}$ from soil, leaving it with $\mathrm{AR}<1$ and the leaching water with AR > 1 (Osmond and Cowart, 1976). The extent of ${ }^{234 / 238} \mathrm{U}$ disequilibrium depends on the characteristics of the disturbance and values of $0.8-10$ in waterbodies, $0.8-8$ in precipitation and 0.5-1.2 in soil have been reported (Keith et al., 2007). The contribution of fertilizer-derived 

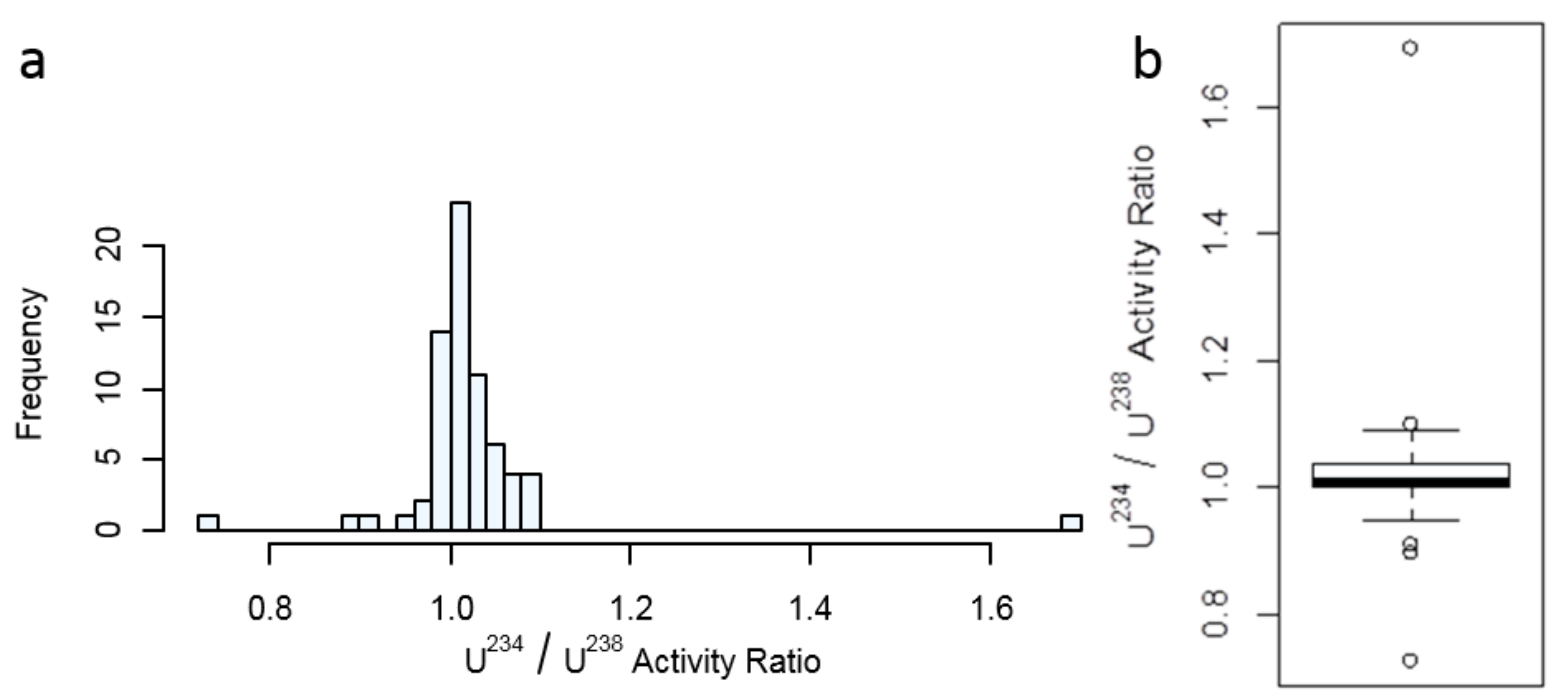

108

Figure 1 a) Frequency distribution of $A R$ in 65 mineral based $P$ fertilizers; b) Boxplot of AR values of $P$ fertilizers. The bold black line in the box, shows the median, the upper and lower end of the box show the upper and lower quantile. The whisker represent the lowest and highest value, which is still within 1.5 times the interquartile range. Dots above and below the whiskers can be considered as outliers. Data from Baeza et al. (2011), Conceicao and Bonotto (2003), Gafvert et al. (2001), Guimond and Windham (1975), Makweba and Holm (1993), Mangini et al. (1979), Osmond and Cowart (1976), Sattouf (2007), Saueia and Mazzilli (2006), Taylor (2007) and Zielinski et al. (1997, 2000, 2006).

To study the influence of fertilizer-derived $U$ on concentrations in soils and its possible leaching, we sampled soils from four agricultural catchments that showed elevated $U$ concentrations in drinking water wells. These areas are under intensive agricultural usage and there is no obvious source of the high $U$ in the water wells. The aims of this study were to determine:

1. whether fertilizer-derived $U$ has the potential to cause significantly elevated $U$ concentrations in ground- and surface waters,

2. whether there is any indication of fertilizer-derived $U$ enrichment in the agricultural soils and,

3. whether there is any indication of $U$ leaching from the soils.

\section{Material and Methods}

\section{Study sites}


Four study locations in the canton of Bern, Switzerland were chosen because of the occurrence of elevated $U$ concentrations in ground- and spring waters (Table 1) nevertheless the geology is very similar to other sites with low $U$ in waters. The locations Oberwil bei Büren (pumping station at Rossmatt), Oberwil bei Büren (well at Rüti), Ins (well) and Walliswil (well) were selected. All locations are in the Swiss molasse basin (Figure S1). The agricultural fields and the nearby forest sites have similar underlying geology (www.geo.admin.ch). The two locations in Oberwil bei Büren (Rossmatt and Rüti) are close to each other and the area is underlain by Quaternary unconsolidated rock, mainly till from the last glaciation (Würm). The forest at Rüti covers the same formation, and the forest at Rossmatt lies on the same formation but is close to Tertiary molasse (Lower Freshwater Molasse) of the Zinshölzli Formation under a thin Quaternary cover. The pumping station at Rossmatt pumps water from 40m depth. The water permeability is classified as normal for all fields, and the water-retention capacity is moderate to good. In Ins the agricultural fields and the forest site are situated on grey-green shell sandstones and marl of the Upper Marine Molasses. The springs are located on clayey marls, freshwater limestone and grey sandstones. The water permeability is characterized as normal with a good water-retention capacity. In Walliswil the area contains Quaternary unconsolidated rocks, probably from the last glaciation (Würm). The water permeability for the Walliswil sites is classified as excessive and the water-retention capacity as low. However, the forest site in Walliswil has a loose surface layer, the highest $\mathrm{C}_{\text {org }}$ concentrations, and a name indicating a historical peat land (Dängelmoos). In addition, local knowledge indicates that the forest site receives significant amounts of drainage water/surface runoff from other agricultural and forested sites. The water chemistry of all waters is dominated by dissolved $\mathrm{Ca}^{2+}(90-131$ $\left.\mathrm{mg} \mathrm{L}^{-1}\right)$ and $\mathrm{Mg}^{2+}\left(5.9-26.9 \mathrm{mg} \mathrm{L}^{-1}\right.$; total hardness $\left.3.3-3.7 \mathrm{mmol} \mathrm{L}^{-1}\right)$, with less $\mathrm{Na}$ (3.3-16 and $\mathrm{K}(0.9-4.6)$ and has a neutral to slightly alkalic $\mathrm{pH}$. The dominating soils are Cambisols, while at some sites also Luvisols might have formed (FAO, 2006). The depth of the ploughed surface horizon is between $25-30 \mathrm{~cm}$, regular manure application is likely on most of the fields. Irrigation of the field sites is unlikely as mainly crops are grown which are not irrigated in this part of Switzerland (wheat, corn, grass etc.; Fuhrer 2014) 
Table 1: Uranium concentrations and AR in drinking water wells

\begin{tabular}{cccc}
\hline Location & $\begin{array}{c}\text { Type of water } \\
\text { (Concession volume [I } \\
\left.\text { min }^{-1}\right] \text { ) }\end{array}$ & $\begin{array}{c}\text { Uranium } \\
\left.\text { concentration [ } \mathbf{\mu g ~ L}^{-1}\right]\end{array}$ & 234/238U Activity Ratio \\
\hline Rossmatt & $\begin{array}{c}\text { Groundwater (101- } \\
\text { 250) }\end{array}$ & 27.97 & 1.22 \\
Rüti & $\begin{array}{c}\text { Spring tap 1 \& 2 (315 } \\
\text { \& 370) }\end{array}$ & 12.01 & 1.22 \\
Walliswil & Groundwater (40) & 7.4 & - \\
Ins & Spring tap (40) & 20.34 & 1.11 \\
& Spring tap 1 (-) & 8.13 & 1.05 \\
Ins & Spring tap 2 (40) & 15.82 & 0.99 \\
Schlosshubel & Spring tap 3 (-) & 12.39 & 1.06 \\
\hline
\end{tabular}

159

\section{Sampling}

At each study site three agricultural fields and one forest were sampled. The arable sites were always located in the direct water protection area (inflow area) of the corresponding drinking water well. The information about the inflow areas are taken from the water protection maps (geoadmin.ch), and are mainly based on test with fluorescent tracers in the past (personal communication Bruno Schlup, responsible person for the Rüti Well). One nearby forest site was chosen at every location as an unfertilized reference site. At each of the sites soil was sampled with a soil auger down to $1 \mathrm{~m}$ depth in ten replicates evenly distributed over the sites. The samples from all sites were separated into subsamples from depths 0-30, 30-60 and 60$100 \mathrm{~cm}$. In addition, for field C at Ins the last depth interval was subdivided because of obvious changes in colour and structure. One composited sample was prepared from the 10 replicates for each depth. In total twelve arable sites and four forest sites were sampled at three depth intervals. For analytical purposes nineteen commercially available fertilizers were bought from shops in the canton of Bern. In total six PK (phosphorous potassium), six superphosphates, six NP (nitrogen phosphorous) and one MKP (monopotassium phosphate) fertilizer were sampled. Water samples were collected from the pumping station and the water wells in plastic bottels, filtered $(0.45 \mu \mathrm{m})$ and acidified $\left(\mathrm{HNO}_{3}\right)$ directly after sampling. 


\section{Soil characterization}

After sampling the 49 soils were dried at $40^{\circ} \mathrm{C}$, aggregates were crushed and the sample was sieved to $\leq 2 \mathrm{~mm}$ using a stainless steel sieve. The $\mathrm{pH}$ was measured in $0.01-\mathrm{M} \mathrm{CaCl}_{2}$ with a soil solution ratio of 1:2.5 after $2 \mathrm{~h}$ using a glass $\mathrm{pH}$ electrode. To determine the effective cation exchange capacity (ECEC) and base saturation, $5 \mathrm{~g}$ of soil was extracted in $100 \mathrm{ml}$ of $1 \mathrm{M}$ ammonium nitrate $\left(\mathrm{NH}_{4} \mathrm{NO}_{3}\right)$ solution on a horizontal shaker for $1 \mathrm{~h}$. The concentrations of calcium (Ca), magnesium $(\mathrm{Mg})$, potassium $(\mathrm{K})$, sodium $(\mathrm{Na})$, manganese $(\mathrm{Mn})$ and aluminium (Al) were measured with flame atom absorption spectrometry (ZEEnit 700P, Analytik Jena). ECEC was then calculated as the sum of the charge of the exchangeable $\mathrm{Ca}^{2+}, \mathrm{Mg}^{2+}, \mathrm{K}^{+}, \mathrm{Na}^{+}$, $\mathrm{Al}^{3+}$ and $\mathrm{Mn}^{2+}$ ions, and is expressed in $\mathrm{mmol}_{\mathrm{c}} \mathrm{kg}^{-1}$. Base saturation was calculated as the percentage of the charge of basic cations $\left(\mathrm{Ca}^{2+}, \mathrm{Mg}^{2+}, \mathrm{K}^{+}\right.$and $\left.\mathrm{Na}^{+}\right)$of the ECEC.

For texture analysis an aliquot of the soil was oxidized by heating with $\mathrm{H}_{2} \mathrm{O}_{2}$ to remove all organic material. Samples were then washed and finally dispersed in a sodium hexametaphosphate/sodium carbonate solution. Particle-size distribution was measured using a laser diffraction particle-size analyser (Mastersizer 2000, Malvern, Herrenberg, Germany). The average relative standard deviation of repeated samples was $8 \%$. For total element concentrations and analysis of carbon, nitrogen and sulphur (CNS), an aliquot of each soil sample was ground in a ball mill in agate beakers (PM 200, Retsch $\mathrm{GmbH}$, Haan, Germany). Rock samples were crushed using a jaw breaker and ground with the same ball mill. The CNS concentrations were analysed by elemental analysis (vario EL cube, Elementar analysesysteme, Hanau, Germany) on both $550^{\circ} \mathrm{C}$-heated (only inorganic C) and untreated (organic and inorganic $\mathrm{C}$ ) samples: the amount of organic $\mathrm{C}\left(\mathrm{C}_{\mathrm{org}}\right)$ was calculated from the difference between the two values.

\section{$\mathrm{U}$ analysis}

The extractable $U$ fraction was extracted in $0.5 \mathrm{~mol} \mathrm{NaHCO}_{3}(\mathrm{pH} 8.5)$ after $16 \mathrm{~h}$ of shaking at a soil/solution ratio of 1:60. After shaking the sample was filtered (Whatman, Grade 589/2) and the supernatant was analysed for $U$ concentrations. Total digestions were performed in a 
microwave oven with $0.1 \mathrm{~g}$ of pulverized sample, $0.5 \mathrm{ml} \mathrm{H}_{2} \mathrm{O}_{2}(30 \%), 2 \mathrm{ml} \mathrm{HF} \mathrm{(40 \% )} \mathrm{and} 2 \mathrm{ml}$ $\mathrm{HNO}_{3}(69 \%)$ at $200^{\circ} \mathrm{C}$ for 40 minutes. A second run was carried out after adding $10 \mathrm{ml}$ of $6 \%$ boric acid $\left(\mathrm{H}_{3} \mathrm{BO}_{3}\right)$, at $180^{\circ} \mathrm{C}$ for 30 minutes to complex the remaining $\mathrm{HF}$. Total digestions of fertilizers were undertaken in $8 \mathrm{ml} \mathrm{HNO}_{3}(69 \%)$ and $2 \mathrm{ml} \mathrm{H}_{2} \mathrm{O}_{2}(30 \%)$ in a microwave oven at $200^{\circ} \mathrm{C}$. Total element concentrations were measured using an inductively coupled plasma mass spectrometer (ICP-MS; 7700x, Agilent Technologies, Palo Alto, CA) with ${ }^{103} \mathrm{Rh}$ and ${ }^{115} \mathrm{In}$ as internal standards. The applied method was tested using standard reference material (BCR-2, United States Geological Survey, Reston, Virginia) and showed good agreement between measured $\left(1.73 \pm 0.08 \mathrm{mg} \mathrm{kg}^{-1}, \mathrm{n}=4\right)$ and certified $\left(1.69 \pm 0.19 \mathrm{mg} \mathrm{kg}^{-1}\right)$ values.

For the AR analysis, $0.1 \mathrm{~g}$ of the pulverized samples were weighed in Savillex beakers and heated on a hotplate in $2.4 \mathrm{ml} \mathrm{HF} \mathrm{(40 \% )} \mathrm{and} 0.8 \mathrm{ml} \mathrm{HNO}$ (69\%, 3:1 ratio) for $48 \mathrm{~h}$. The digest was dried down and the remaining residues treated with $750 \mu \mathrm{HCl}$ and $250 \mu \mathrm{HNO}$ (3:1 ratio) and evaporated. The samples were redissolved in $4 \mathrm{ml}$ of $3 \mathrm{M} \mathrm{HNO}_{3}$ and purified following the method of Weyer et al. (2008) on UTEVA (Eichrom Technologies Inc.) U specific resin. We modified the method using $9 \mathrm{M} \mathrm{HCl}$ to convert the columns from the nitric to the chloric system as proposed by the manufacturer of the columns (Eichrom Technologies Inc., 2005). The purification procedure showed good separation of $U$ (Figure S2). In total, 99\% of the total eluted $U$ was collected in the $U$ fraction and the concentrations of Th and Fe were less than $0.1 \%$ of that of $U$. Recovery rates for the BCR-2 reference material after column purification were $90 \% \pm 9 \%(n=3)$, comparable to the results of Grinberg et al. (2005). The recoveries were considered sufficient because the isotope ratio is not affected by the separation process (Weyer et al., 2008). The total blank of the method was $<0.4 \%$ of the lowest concentrations in a sample.

Isotope ratios were analysed on the same Quadrupole ICP-MS as was used for the element concentrations. Before analysis, all standards and samples were diluted to a concentration of $12.5 \mu \mathrm{g} \mathrm{L}^{-1}$ and the instrument settings were adjusted to allow highly accurate $\mathrm{U}$ isotope analysis (five replicates, 1000 sweeps/replicate, integration time $0.3,0.3,0.99,50.01,5.01$ and 0.99 seconds for mass 103, 115, 232, 234, 235 and 238, respectively). ${ }^{103} \mathrm{Rh}$ and ${ }^{115} \mathrm{In}$ 
were used as internal standards and ${ }^{232} \mathrm{Th}$ was monitored to detect possible interference. The isotope ratio was mass bias corrected using the standard bracketing method (Albarède and Beard, 2004). IRMM 3184 (Institute for Reference Materials and Measurements, Geel, Belgium) was used as the bracketing standard. The measured isotope ratios were transformed to activity ratios using the specific activity of each isotope. We repeatedly analysed BCR-2 for quality control. The results $(1.000 \pm 0.004$, mean $\pm S D, n=12)$ agree well with the values of $1.000 \pm 0.001$ reported by Beier et al. $(2010 a, b)$ and of $1.001 \pm 0.002$ reported by Keech et al. (2013). The overall reproducibility was similar for the BCR $( \pm 0.004, S D, n=12)$, an in house standard $( \pm 0.004, S D, n=6)$ and repeated sample digests $( \pm 0.007, S D, n=6)$ and sufficient at the overall variation of $A R$ in the samples (0.906-1.065).

\section{Assessment of possible U leaching}

Using available information about fertilizer use in Switzerland (Agristat, 2013; BLW, 2014; GRUDAF, 2009) and the $U$ concentrations in the fertilizers, estimates of $U$ leaching were obtained on an annual basis. The estimate of the possible contribution of fertilizer-derived $U$ to the $U$ concentration in water was based on certain assumptions. Two scenarios were tested. The first scenario, the "average scenario", was based on average values for fertilizer application (GRUDAF, 2009), U content in the fertilizer (Figure 2), leaching rate and infiltration rate (von Gunten, 2000). A second estimate was calculated using a "high scenario" with a high fertilizer application rate (for fodder beet, the culture with the highest $\mathrm{P}$ demand according to GRUDAF [2009]). A correction factor of 1.25 was applied, what means that $25 \%$ more fertilizer can be applied to compensate for lower than normal P concentrations in the soil. For the high scenario, a fertilizer with high $U$ concentration $\left(90^{\text {th }}\right.$ percentile, Figure 2$)$, the maximum leaching rate and a high infiltration rate was assumed (von Gunten, 2000). The maximum correction factor for P fertilization according to GRUDAF (2009) was not applied because it seems unlikely that a P-demanding crop is cultivated on a field where such a correction factor would apply. The infiltration on the Swiss Plateau is $250-700 \mathrm{~mm} \mathrm{a}^{-1}$ (Von Gunten, 2000). 


\section{Statistical Analysis and geochemical mass balancing}

Differences between groups (e.g., between forest and arable soils) were tested using a two sided t test.

Geochemical mass balances of $U$ were calculated as $\tau$-values following Brimhall et al. (1992) using $\mathrm{Ti}$ as an immobile element. The $\tau$-value is a measure for the depletion (negative value) or enrichment (positive value) of an element in a soil relative to the bedrock and corrected with an immobile element. A $\tau$-value of 0.5 for example would indicate an enrichment of $U$ by $50 \%$ compared to the bedrock.

271

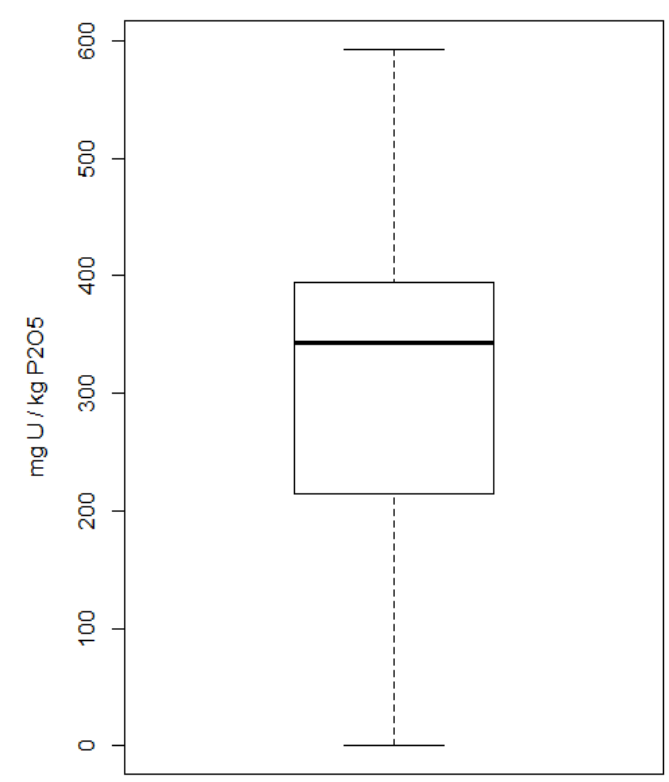

Figure 2: Boxplot of $U$ concentrations in 19 mineral based P-fertilizers sampled in the canton of Bern. The bold black line in the box, shows the median and the upper and lower end of the box show the upper and lower quantile. The whisker represent the lowest and highest value, which is still within 1.5 times the interquartile range.

\section{Results}

The mean $\mathrm{U}$ concentration in the analysed fertilizers was $294 \mathrm{mg} \mathrm{kg}^{-1} \mathrm{P}_{2} \mathrm{O}_{5}$; the median value was $343 \mathrm{mg} \mathrm{kg}^{-1} \mathrm{P}_{2} \mathrm{O}_{5}$ (Figure 2, Table S1). The lowest and highest $U$ concentrations were 0.21 and $593 \mathrm{mg} \mathrm{kg}^{-1} \mathrm{P}_{2} \mathrm{O}_{5}$. The mean and median $\mathrm{U}$ concentrations compared to the dry weight of fertilizer were 77.8 and $69.6 \mathrm{mg} \mathrm{kg}^{-1}$, with a range of $0.11-188 \mathrm{mg} \mathrm{kg}^{-1}$. Comparably 
high concentrations were detected for PK (mean $386 \mathrm{mg} \mathrm{kg}^{-1} \mathrm{P}_{2} \mathrm{O}_{5} ; \mathrm{n}=4$ ), superphosphate (mean $358 \mathrm{mg} \mathrm{kg}^{-1} \mathrm{P}_{2} \mathrm{O}_{5} ; \mathrm{n}=4$ ) and NP-fertilizers (mean $348 \mathrm{mg} \mathrm{kg}^{-1} \mathrm{P}_{2} \mathrm{O}_{5} ; \mathrm{n}=4$ ), whereas DAP $U$ concentrations were one order of magnitude lower (mean $25.1 \mathrm{mg} \mathrm{kg}^{-1} \mathrm{P}_{2} \mathrm{O}_{5} ; \mathrm{n}=3$ ). The assessment of the possible contributions of fertilizer-derived $U$ to the $U$ concentrations of leaching water indicated significant contributions (Table 2), compared to concentrations in Swiss drinking waters (median $0.77 \mu \mathrm{g} \mathrm{L}^{-1}$; Stalder et al., 2012). However, even in the rather unlikely high scenario, fertilizer-derived $U$ does not cause exceedance of the World Health Organisation (WHO) threshold level for drinking water $\left(30 \mu \mathrm{L} \mathrm{L}^{-1}\right)$.

Table 2: Estimation of the possible contribution of mineral based $P$ fertilizers to $U$ in groundand well water.

\begin{tabular}{ccc}
\hline & “Average" scenario & “High" scenario \\
\hline $\begin{array}{c}\text { Mineral based fertilizer } \\
\text { application rate }\end{array}$ & $36.8 \mathrm{~kg} \mathrm{P}_{2} \mathrm{O}_{5} \mathrm{ha}^{-1}$ & $150 \mathrm{~kg} \mathrm{P}_{2} \mathrm{O}_{5} \mathrm{ha}^{-1}$ \\
$\mathrm{U}$ concentration in fertilizer & $294 \mathrm{mg} \mathrm{kg}^{-1} \mathrm{P}_{2} \mathrm{O}_{5}$ & $509 \mathrm{mg} \mathrm{kg}^{-1} \mathrm{P}_{2} \mathrm{O}_{5}$ \\
$\mathrm{U}$ input via fertilization & $10.8 \mathrm{~g} \mathrm{ha}^{-1}$ & $76.4 \mathrm{~g} \mathrm{ha}^{-1}$ \\
Infiltration rate & $600 \mathrm{~mm} \mathrm{a}^{-1}$ & $300 \mathrm{~mm} \mathrm{a}^{-1}$ \\
Leaching amount & $50 \%$ & $100 \%$ \\
$\begin{array}{c}\text { U concentration in } \\
\text { leaching water }\end{array}$ & $\mathbf{1 . 8 0 ~} \mathbf{~ g ~ L ~ L}^{-1}$ & $\mathbf{2 5 . 5} \mathbf{~ g ~ ~ L}^{-1}$ \\
\hline
\end{tabular}

The forest soils showed generally lower $\mathrm{pH}$ and ECEC values than the arable soils. Only the Walliswil arable sites exhibited lower $\mathrm{pH}$ and ECEC values than the forest site (Table 3). The deviation in soil properties and AR in the Walliswil forest site can be explained by the fact that the soil was located at slightly lower elevation than the arable area and probably received leaching water that was enriched in nutrients, carbonate and $U$ with $A R>1$. High soil moisture caused a relative accumulation of organic carbon (Table 3), which could lead to U sorption to organic compounds or precipitation under anaerobic conditions in the peat (Regenspurg et al., 2010). This was also confirmed by the visual impression of the site at the 
time of sampling. The topsoil had quite a large organic overlay, probably caused by reduced decomposition under wet conditions. The name of the site (Dänglermoos) and personal communication with farmers indicate that the area is a former peatland. A cluster analysis based on the soil properties of all soils confirmed that the Walliswil forest site is different from all other soils. Because of these extraordinary features, the forest site at Walliswil was excluded from further comparison and is not included in Figures 3-4.

In contrast, $\mathrm{C}_{\text {org }}$ was always higher in the forest topsoils. Except for these differences, forest soils did not differ from agricultural soils. The difference in the mean $U$ concentration between fields and forests of $0.15 \mathrm{mg} \mathrm{kg}^{-1}$ (Figure S3, S4) was statistically not significant $(p=0.21$ ), which might, however, also be attributable to the small number of samples (especially for the forest sites) and the variation between the individual sites. The $\cup_{\mathrm{NaHCO}}$ concentrations also exhibited a tendency to be higher at arable sites compared to forest soils, but this difference was not significant at all depths (Table 3). The $\tau_{\cup}$ values tend to be lower in forests compared to agricultural fields at each individual site except Walliswil, although these differences are only marginally statistically significant $(p=0.07)$. The difference was about 0.2 over the whole depth of the profile, indicating about $20 \%$ more loss of $U$ at the forest sites (Figure $3 a$ ). In addition, Cd, which has a high concentration in mineral based P-fertilizers (McLaughlin et al., 1996), exhibited no significant enrichment in the arable sites compared to the forest ones ( $p=$ 0.77; Figure $3 b)$, whereas this difference was highly significant for $\mathrm{P}$ down to $60 \mathrm{~cm}$ depth (0$30 \mathrm{~cm}, \mathrm{p}=0.001 ; 30-60 \mathrm{~cm}, \mathrm{p}<0.001 ;$ Figure 3c).

The AR values were generally not different or higher in agricultural topsoils compared to subsoils (Figure S5, S6, Table 3). Compared to forest soils, the AR values at the agricultural sites were only consistently higher in Rossmatt, but were overlapping in Ins and Rüti and clearly lower in Walliswil. Overall, there is a highly significant correlation $(p<0.001)$ between the amount of extractable $U$ and AR (Figure 4). However, for individual sites the correlation is significant for Rossmatt $(p<0.001)$, Walliswil $(p<0.001)$, and marginally significant for Ins ( $p$ $=0.08)$ but not significant for Rüti $(p=0.62$; Figure S4). The AR values in the well water were between 0.99 and 1.22 (Table 1). 
333

334 


\begin{tabular}{|c|c|c|c|c|c|c|c|c|c|c|c|c|c|c|c|c|}
\hline Site & Field & $\begin{array}{l}\text { Depth } \\
{[\mathrm{cm}]}\end{array}$ & $\mathrm{pH}$ & $\begin{array}{c}\text { CEC } \\
{\left[\mathrm{mmol}^{2}\right.} \\
\left.\mathrm{kg}^{-1}\right]\end{array}$ & $\begin{array}{c}\text { Base } \\
\text { sat. }\end{array}$ & Clay & Silt & Sand & Corg & $P$ & $\mathrm{Cd}$ & {$[\mathrm{mg} \mathrm{k}$} & $U_{\text {total }}$ & $\bigcup_{\mathrm{NaHCO} 3}$ & $\begin{array}{l}\text { 234/238U } \\
\text { Activity }\end{array}$ & Ratio \\
\hline \multirow{13}{*}{ 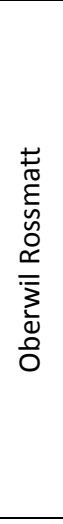 } & & $0-30$ & 3.9 & 34 & 42 & 10 & 35 & 56 & 1.70 & 389 & 0.14 & 6.85 & 2.02 & 0.13 & 0.940 & 0.005 \\
\hline & Forest & $30-60$ & 4.0 & 27 & 30 & 7 & 25 & 68 & 0.62 & 248 & 0.09 & 6.30 & 1.54 & 0.14 & 0.937 & 0.002 \\
\hline & & $60-100$ & 6.4 & 151 & 100 & 9 & 31 & 60 & 0.26 & 304 & 0.11 & 7.66 & 1.68 & 0.05 & 0.930 & 0.004 \\
\hline & & $0-30$ & 5.1 & 67 & 99 & 8 & 39 & 53 & 1.31 & 741 & 0.23 & 5.96 & 2.29 & 0.24 & 1.001 & 0.004 \\
\hline & Field A & $30-60$ & 5.4 & 74 & 99 & 7 & 37 & 56 & 0.83 & 511 & 0.17 & 6.29 & 2.17 & 0.25 & 0.994 & 0.006 \\
\hline & & $60-100$ & 6.8 & - & 100 & 9 & 43 & 48 & 0.51 & 294 & 0.13 & 5.64 & 1.89 & 0.22 & 0.999 & 0.001 \\
\hline & & $0-30$ & 5.5 & 64 & 99 & 8 & 35 & 57 & 1.24 & 708 & 0.20 & 6.08 & 1.99 & 0.30 & 1.007 & 0.023 \\
\hline & Field B & $30-60$ & 5.5 & 63 & 99 & 7 & 34 & 58 & 0.63 & 584 & 0.17 & 6.77 & 1.93 & 0.17 & 0.964 & 0.001 \\
\hline & & $60-100$ & 5.5 & 68 & 100 & 6 & 30 & 64 & 0.34 & 582 & 0.17 & 6.75 & 1.86 & 0.14 & 0.967 & 0.001 \\
\hline & & $0-30$ & 5.6 & 101 & 100 & 10 & 43 & 47 & 1.67 & 612 & 0.18 & 5.62 & 1.64 & 0.57 & 1.054 & 0.005 \\
\hline & Field C & $30-60$ & 5.8 & 81 & 100 & 9 & 37 & 55 & 0.96 & 532 & 0.17 & 6.21 & 2.06 & 0.32 & 1.046 & 0.006 \\
\hline & & $60-100$ & 5.8 & 68 & 100 & 8 & 34 & 58 & 0.45 & 438 & 0.14 & 6.82 & 1.94 & 0.49 & 1.036 & 0.004 \\
\hline & Rock & - & - & - & - & - & - & - & - & 707 & 0.11 & 3.79 & 1.21 & - & 0.922 & 0.005 \\
\hline \multirow{13}{*}{$\begin{array}{l}\overline{\overline{3}} \\
\overline{\bar{n}} \\
3\end{array}$} & & $0-30$ & 6.2 & - & 100 & 7 & 38 & 55 & 4.36 & 903 & 0.40 & 5.81 & 2.03 & 0.37 & 1.006 & 0.004 \\
\hline & Forest & $30-60$ & 6.4 & - & 100 & 9 & 41 & 50 & 2.49 & 890 & 0.25 & 6.86 & 2.50 & 0.55 & 1.036 & 0.006 \\
\hline & & $60-100$ & 6.4 & - & 100 & 9 & 45 & 46 & 1.52 & 806 & 0.26 & 7.02 & 2.52 & 0.69 & 1.065 & 0.007 \\
\hline & & $0-30$ & 5.4 & 64 & 99 & 8 & 55 & 37 & 1.31 & 871 & 0.20 & 7.10 & 2.23 & 0.24 & 0.975 & 0.004 \\
\hline & Field A & $30-60$ & 5.1 & 52 & 100 & 9 & 58 & 33 & 0.75 & 758 & 0.18 & 8.50 & 2.21 & 0.18 & 56 & 0.001 \\
\hline & & $60-100$ & 5.0 & 64 & 100 & 6 & 44 & 50 & 0.35 & 476 & 0.12 & 8.73 & 2.17 & 0.15 & 0.939 & 0.000 \\
\hline & & $0-30$ & 5.2 & 75 & 99 & 10 & 40 & 51 & 2.53 & 1222 & 0.22 & 6.73 & 1.95 & 0.20 & 0.966 & 0.002 \\
\hline & Field B & $30-60$ & 5.1 & 51 & 100 & 8 & 34 & 58 & 1.37 & 814 & 0.17 & 6.77 & 1.76 & 0.18 & 0.959 & 0.005 \\
\hline & & $60-100$ & 5.3 & 43 & 99 & 12 & 37 & 52 & 0.63 & 565 & 0.13 & 7.32 & 2.09 & 0.15 & 0.906 & 0.002 \\
\hline & & $0-30$ & 5.5 & 72 & 100 & 10 & 41 & 49 & 1.81 & 1386 & 0.27 & 5.94 & 1.96 & 0.31 & 0.968 & 0.000 \\
\hline & Field C & $30-60$ & 5.0 & 37 & 99 & 9 & 34 & 57 & 1.04 & 792 & 0.20 & 6.16 & 1.85 & 0.21 & 0.962 & 0.005 \\
\hline & & $60-100$ & 5.1 & 38 & 99 & 7 & 33 & 60 & 0.46 & 453 & 0.43 & 7.47 & 1.95 & 0.15 & 0.945 & 0.003 \\
\hline & Rock & - & - & - & - & - & - & - & - & 699 & 0.21 & 4.03 & 0.97 & - & 0.985 & 0.005 \\
\hline \multirow{13}{*}{ 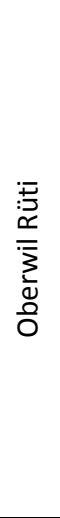 } & & $0-30$ & 4.3 & 41 & 83 & 7 & 40 & 53 & 1.50 & 303 & 0.14 & 6.37 & 1.82 & 0.19 & 0.980 & 0.003 \\
\hline & Forest & $30-60$ & 4.4 & 59 & 89 & 7 & 49 & 43 & 0.48 & 256 & 0.33 & 8.68 & 2.20 & 0.19 & 0.972 & 0.004 \\
\hline & & $60-100$ & 4.8 & 86 & 93 & 6 & 51 & 43 & 0.16 & 423 & 0.19 & 9.57 & 2.38 & 0.11 & 0.980 & 0.002 \\
\hline & & $0-30$ & 5.1 & 63 & 95 & 6 & 40 & 54 & 1.02 & 685 & 0.42 & 6.40 & 2.11 & 0.24 & 0.971 & 0.012 \\
\hline & Field A & $30-60$ & 5.4 & 82 & 93 & 7 & 43 & 51 & 0.32 & 395 & 0.16 & 8.18 & 2.40 & 0.17 & 0.973 & 0.005 \\
\hline & & $60-100$ & 5.6 & 93 & 100 & 7 & 52 & 41 & 0.12 & 466 & 0.17 & 9.03 & 2.43 & 0.14 & 0.963 & 0.004 \\
\hline & & $0-30$ & 6.0 & 91 & 100 & 8 & 52 & 40 & 1.27 & 737 & 0.39 & 7.43 & 2.33 & 0.20 & 0.949 & 0.003 \\
\hline & Field B & $30-60$ & 5.7 & 87 & 100 & 5 & 37 & 58 & 0.67 & 521 & 0.16 & 8.75 & 2.20 & 0.13 & 0.954 & 0.001 \\
\hline & & $60-100$ & 6.9 & 89 & 100 & 8 & 55 & 37 & 0.23 & 607 & 0.17 & 5.19 & 1.97 & 0.11 & 0.903 & 0.002 \\
\hline & & $0-30$ & 5.8 & 95 & 100 & 9 & 49 & 42 & 1.03 & 782 & 0.18 & 7.12 & 2.24 & 0.21 & 0.964 & 0.002 \\
\hline & Field C & $30-60$ & 5.9 & 94 & 100 & 8 & 45 & 47 & 0.33 & 713 & 0.18 & 7.65 & 2.21 & 0.18 & 0.959 & 0.005 \\
\hline & & $60-100$ & 5.7 & 89 & 100 & 7 & 47 & 46 & 0.18 & 551 & 0.19 & 8.49 & 2.42 & 0.13 & 0.933 & 0.001 \\
\hline & Rock & - & - & - & - & - & - & - & - & 531 & 0.12 & 5.82 & 2.25 & - & 0.969 & 0.003 \\
\hline \multirow{14}{*}{$\stackrel{n}{\subseteq}$} & & $0-30$ & 3.9 & 59 & 47 & 10 & 47 & 44 & 1.69 & 341 & 0.31 & 5.24 & 1.89 & 0.23 & 0.986 & 0.006 \\
\hline & Forest & $30-60$ & 4.1 & 42 & 92 & 8 & 42 & 49 & 0.56 & 227 & 0.08 & 7.03 & 2.34 & 0.25 & 0.979 & 0.004 \\
\hline & & $60-100$ & 4.6 & 92 & 99 & 10 & 45 & 44 & 0.26 & 482 & 0.10 & 9.42 & 2.64 & 0.23 & 0.967 & 0.006 \\
\hline & & $0-30$ & 4.5 & 68 & 99 & 6 & 33 & 60 & 1.22 & 501 & 0.10 & 6.01 & 1.58 & 0.21 & 0.979 & 0.013 \\
\hline & Field A & $30-60$ & 5.1 & 76 & 99 & 6 & 34 & 60 & 0.81 & 540 & 0.08 & 7.66 & 1.79 & 0.16 & 0.965 & 0.004 \\
\hline & & $60-100$ & 5.2 & 89 & 100 & 5 & 29 & 66 & 0.65 & 501 & 0.07 & 8.37 & 1.95 & 0.13 & 0.971 & 0.008 \\
\hline & \multirow{4}{*}{ Field B } & $0-30$ & 5.7 & 91 & 100 & 8 & 39 & 53 & 0.95 & 641 & 0.15 & 5.85 & 2.19 & 0.37 & 0.976 & 0.021 \\
\hline & & $30-60$ & 5.7 & 97 & 100 & 9 & 38 & 53 & 0.55 & 438 & 0.12 & 6.64 & 2.47 & 0.51 & 0.989 & 0.006 \\
\hline & & $60-100$ & 5.9 & - & 100 & 9 & 41 & 50 & 0.29 & 362 & 0.10 & 7.52 & 2.69 & 0.40 & 0.987 & 0.006 \\
\hline & & $0-30$ & 6.0 & 73 & 100 & 8 & 41 & 51 & 0.95 & 506 & 0.80 & 6.00 & 2.14 & 0.25 & 0.998 & 0.004 \\
\hline & \multirow{3}{*}{ Field C } & $30-60$ & 5.9 & 66 & 100 & 10 & 42 & 48 & 0.63 & 371 & 0.10 & 6.05 & 1.96 & 0.22 & 0.993 & 0.001 \\
\hline & & $60-90$ & 5.8 & 82 & 100 & 7 & 40 & 53 & 0.27 & 286 & 0.08 & 7.15 & 2.32 & 0.17 & 1.006 & 0.010 \\
\hline & & $90-100$ & 5.9 & 95 & 100 & 9 & 48 & 43 & 0.18 & 258 & 0.08 & 7.69 & 2.31 & 0.17 & 1.000 & 0.003 \\
\hline & Rock & - & - & - & - & - & - & - & - & 372 & 0.04 & 7.12 & 1.98 & - & 0.954 & 0.001 \\
\hline
\end{tabular}




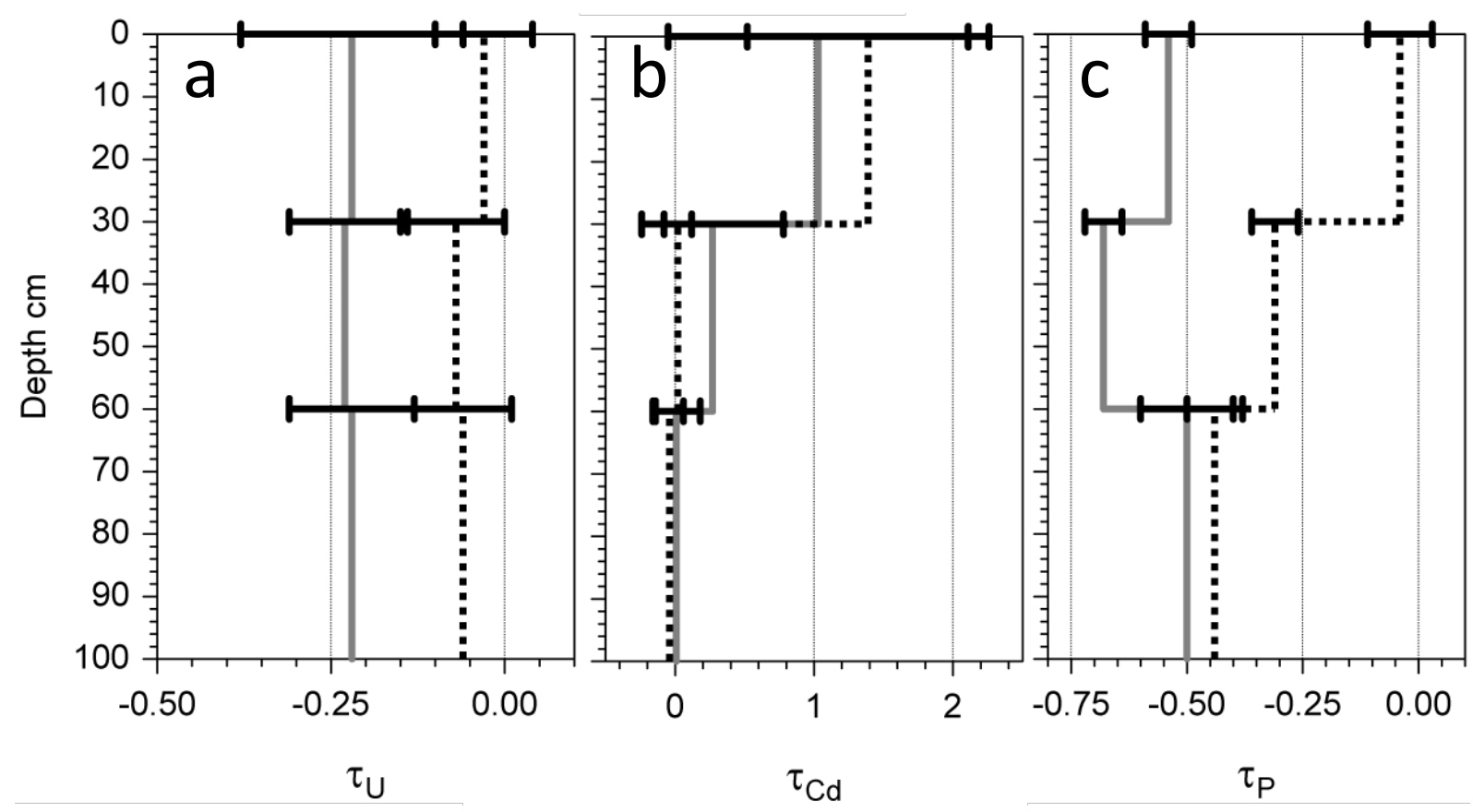

Figure 3 The a) $\left.\tau_{\cup}, b\right) \tau_{C d}$ and c) $\tau_{P}$ values of the field and forest soils. Solid grey lines denote forest sites; dotted black lines represent arable fields.

\section{Discussion}

\section{General assessment of the possible impact of fertilizer-derived $U$ on drinking water.}

The possible effect of fertilizer-derived $U$ on soils and leaching water has been assessed based on the $U$ concentrations in the investigated mineral based fertilizers (Figure 2), official fertilization recommendations for different crop types, infiltration rates from the literature, and assumed leaching rates, for both an average and a high scenario (Table 2).

The assumed $U$ input via fertilization for the average scenario falls well within the range of literature values: 0.13-61 $\mathrm{g} \mathrm{ha}^{-1}$ (Kratz et al., 2008) and 2.8-16 $\mathrm{g} \mathrm{ha}^{-1} \mathrm{a}^{-1}$ (Uterman and Fuchs, 2008) in Germany; 15 and $16 \mathrm{~g} \mathrm{ha}^{-1} \mathrm{a}^{-1}$ at two sites in England and New Zealand (Rothbaum et al., 1979). The values in the high scenario seem reasonable, as $U$ application in Switzerland has been reported to reach up to $110 \mathrm{~g} \mathrm{ha}^{-1} \mathrm{a}^{-1}$ for certain sites with high-P-demand crops and purely mineral based fertilization in certain years (Bigalke et al., 2017). The most critical aspect of the assessment of $U$ concentrations in leaching water is surely the amount of $U$ leached. In this study, $50 \%$ or even $100 \%$ is probably an overestimation for most sites; however, the $100 \%$ approach is taken to estimate the maximal possible fertilizer-derived $U$ concentration in leaching water. 
Uranium output by plant uptake and crop harvesting was estimated to be less than $1 \mathrm{~g} \mathrm{ha} \mathrm{h}^{-1}$ (Kratz et al., 2008), leaving 9.8-75 $\mathrm{g} \mathrm{ha}^{-1} \mathrm{a}^{-1}$ in either the soil or leachates (Table 2). Translating this into an increase in $U$ concentration in the topsoils $(30 \mathrm{~cm}$ depth, density $1 \mathrm{~kg}$ $\mathrm{cm}^{-3}$ ) yields a value of $3.3-25 \mu \mathrm{kg}^{-1} \mathrm{a}^{-1}$, in good agreement with the compiled annual $\mathrm{U}$ accumulation rates in topsoil (0-20 or $0-30 \mathrm{~cm}$ depth) of $1-46 \mu \mathrm{g} \mathrm{kg}^{-1}$ from long-term fertilization experiments (Rogasik et al., 2008, Taylor and Kim, 2008). This similarity of $U$ inputs and enrichment in soil indicates that a considerable amount of the applied $U$ is retained in the soil. However, Barisic et al. (1992) estimated that $20 \%$ of applied fertilizers are transported to drainage channels, whereas Conceicao and Bonotto (2003) assumed that $30 \%-43 \%$ of $U$ in river water is derived from fertilizer application. Furthermore, Rogasik et al. (2008) detected strong differences in the accumulation rates related to different soil properties; conversely, certain soils did not immobilize $U$ to the same extent as others. Therefore, estimation of leached $U$ is quite difficult because of the high uncertainty and lack of measured values. The estimations (Table 2) illustrate that under extreme circumstances (e.g., shallow groundwater, sandy soil, high-P-demand crop, high $U$ concentration in fertilizer) fertilizer-derived $U$ might cause the $U$ concentration in groundwater to be close to the WHO threshold value and to exceed the threshold for drinking water of some countries (e.g., Germany, $10 \mu \mathrm{g} \mathrm{L}^{-1}$ ). However, while we assume these extreme cases to be rare, under normal circumstances fertilizerderived $U$ will not reach values close to the Swiss threshold values but might however significantly contribute to $U$ concentrations in normal Swiss groundwater (median values in

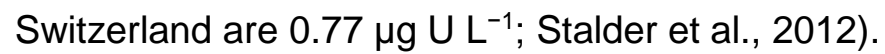

Our results fit published results from the literature as an increase in $U$ concentrations in ground water derived from fertilizers has also been shown also in a number of other studies (Azouazi et al., 2001; Barisic et al., 1992; Birke and Rauch, 2008; Conceicao and Bonotto, 2003; Huhle et al., 2008; Zielinski et al., 2000). As an example, near-surface groundwater is 3-17-fold enriched in $U$ in agricultural areas (Huhle et al., 2008) and $U$ concentrations in water in the former West Germany are reported to be higher than in water in the former East Germany ( 0.741 and $0.462 \mu \mathrm{g} \mathrm{L}^{-1}$, respectively). The latter has been explained by the lower intensity of 
P-fertilization and lower U concentration (P from igneous rocks; Birke and Rauch, 2008; Schulz et al., 2003). In a broad study of $U$ concentrations in drinking water in Switzerland it was determined that elevated concentrations (up to $100 \mathrm{\mu g} \mathrm{L}^{-1}$ ) were only attributable to geological factors (Stalder et al., 2012). However, for that study important cantons (e.g., Bern, where our study sites are located) on the Swiss Plateau were not included and fertilizer-derived $U$ was not considered as a source of $U$. Other studies investigated high $U$ concentrations in surface waters and found geological factors to be responsible for the elevated concentrations (Banning et al., 2013; Schott and Wiegand, 2003; Zielinski et al., 1995, 1997).

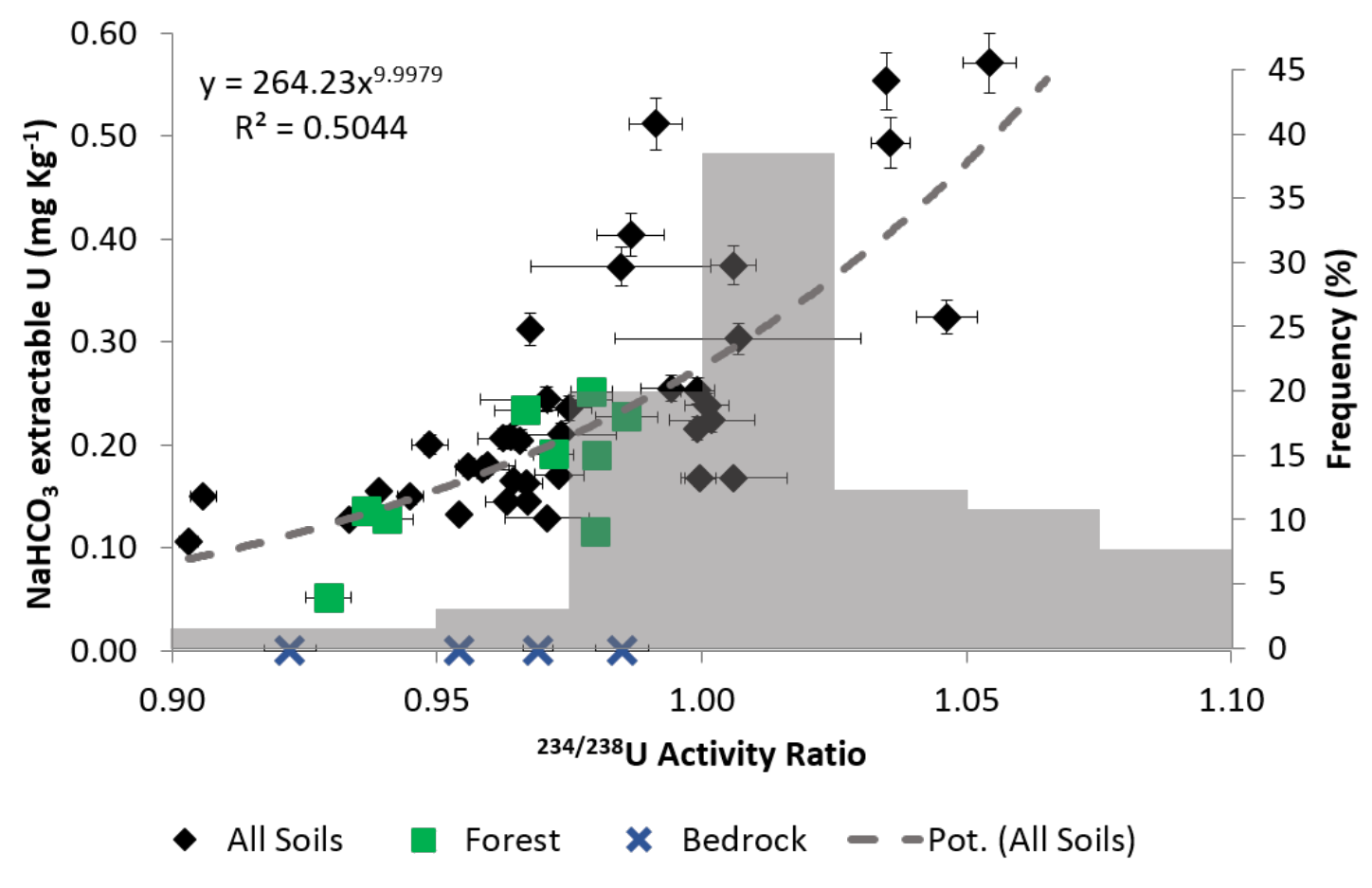

Figure 4: Exponential relationship between $\mathrm{AR}$ and $\mathrm{NaHCO}_{3}$-extractable $\mathrm{U}$ fraction. The grey bars are the frequency (\%) histogram of fertilizer AR values (Figure 1).

\section{Enrichment and sources of $U$ in agricultural soils}

Although in our study area $U$ was not significantly enriched at the arable sites (Figures S3), comparable studies reported significant enrichments of $0.1-1.3 \mathrm{mg} \mathrm{U} \mathrm{kg}^{-1}$ in fertilized soils (Ahmed et al., 2014; Bigalke et al., 2017; Huhle et al., 2008; Rogasik et al., 2008; Rothbaum et al., 1979; Taylor, 2007). The reasons for the broad range might be different sampling depths, different fertilization rates (up to $500-600 \mathrm{~kg}$ triple superphosphate $\mathrm{ha}^{-1} \mathrm{a}^{-1}$; Taylor, 2007), 
different $U$ concentrations in the fertilizers and different soil properties $(\mathrm{pH}$, organic matter, redox conditions; Rogasik et al., 2008; Rothbaum et al., 1979). However, many of the soils in the studies received mineral based P-fertilizers annually, whereas in the studied soils, manure application might account for a significant part of the fertilization. Insignificant $\mathrm{U}$ accumulation in the surface soil at the studied sites might be partly attributable to surface erosion or leaching of $U$ from the soil.

In Rossmatt, Rüti and Ins the AR values of the forest soils are close to those of the local bedrock, but some arable soils exhibit significant deviations (Figures S5, S6, Table 3). Although soil formation should normally lead to AR values smaller than that of the bedrock, this is only the case for Walliswil (except Walliswil forest soils) and Rüti. In contrast Rossmatt and Ins show higher AR compared to the bedrock, indicating higher proportions of fertilizerderived $U$, which overcompensate for the weathering effect on the AR (Figures S5, S6).

The overall correlation between extractable $U$ and $A R$ indicates a link between high fertilizer $\mathrm{U}$ input and the amount of weakly bound $\mathrm{U}$ in the soil. As the $\mathrm{NaHCO}_{3}$-extractable $\mathrm{U}$ has a higher mobility compared to the rest of the total $U$, this correlation indicates a contribution of fertilizer derived $U$ to $U$ leaching. The lack of correlation for the Rüti and Ins site might be caused by the topography of the sites. The sites are located on top- and midslope positionsand erosion might eliminate clear patterns because of constant loss of surface soil. On the other hand lateral water flow down the slope might affect $A R$, because of leaching water with $A R>1$, which might be sorbed and increase AR of the soil at positions down the slope.

\section{Leaching of $U$ in fertilized soils}

The distributions of $U$ concentrations, $\tau_{\cup}$ values and AR values do not exhibit obvious depth gradients (Figures 3, 4, S3-S6). In contrast, the depth gradient is very significant for $\mathrm{P}$, the main component of the mineral based P-fertilizers (Figure 3, Table S1). These differences might be attributable to the much higher $\mathrm{P}$ contents compared to the $\mathrm{U}$ contents of the fertilizers and the different background concentrations in the soil and to manure fertilization, with low $U$ contents. Assessment of the possible $U$ input in the topsoil $(0-30 \mathrm{~cm})$ from the $P$ 
enrichment in the topsoil, based on the mean $U$ concentrations of the fertilizers (Figure 2)

432

433

434

435

436

437

438

suggests the $U$ enrichment in the topsoil compared to the subsoil would be around $0.25 \mathrm{mg}$ $\mathrm{kg}^{-1}$. This is close to our (non-significant) mean difference of $0.15 \mathrm{mg} \mathrm{kg}^{-1}$ between forest and agricultural sites and to $U$ enrichments reported in Swiss agricultural topsoil compared to subsoils (mean $0.19 \mathrm{mg} \mathrm{kg}^{-1}$; Bigalke et al., 2017). However, while it is well known that high amounts of $\mathrm{P}$ are extracted from the soil by plant growth and exported from the soil via harvest, this is not the case for $\mathrm{U}$. Conversely, manure can provide significant inputs of $\mathrm{P}$ without adding large amounts of $U$ to the soil. The mean AR ratios show a tendency to be higher in the arable soils, but clearly overlap with the AR values of forest soils and bedrock. Overall, the lack of a $U$ depth gradient indicates a lack of accumulation in the topsoil and thus might suggest $U$ leaching or erosion. However, $U$ might also be sorbed in deeper soil and rock layers, depending on the solution chemistry and speciation of $U$, and will not necessarily end up in ground- and spring water. In the literature, fertilizer-derived $U$ concentrations in ground- and surface waters were mostly estimated to be $<0.5 \mu \mathrm{g} \mathrm{L}{ }^{-1}$ (Birke and Rauch, 2008; Conceicao and Bonotto, 2003; Zielinski et al., 2006) but may reach up to $3.4 \mathrm{\mu g} \mathrm{L}^{-1}$ in drainage water and near-surface groundwater directly in arable fields (Huhle et al., 2008; Zielinski et al., 2000). However, at out study sites the ground- and spring water reservoirs are comparatively deep (many sorption sites), some fertilization was in the form of manure, and not all of the catchment was covered by arable sites. Thus, we assume that contribution to groundwater would rather be lower than the average scenario we calculated (Table 2). From these assumptions, we roughly estimate that leaching of fertilizer-derived $U$ to ground- and spring water is probably less than approx. $2 \mu \mathrm{g} \mathrm{L} \mathrm{L}^{-1}$. Comparing this value to the elevated $\mathrm{U}$ concentrations in the wells, it becomes clear that there must be additional sources for the elevated U concentrations.

The AR values in natural, unpolluted water samples are 1-4, while a value close to $1 \mathrm{might}$ indicate fertilizer-derived $U$ in the water (Zielinski et al., 1997, 2000, 2006). Thus, the AR values in the waters at our study sites (Table 1) might indicate fertilizer-derived $U$ input, but also a geological basis cannot be excluded. 


\section{Conclusions}

- Fertilizer-derived $U$ can theoretically cause high $U$ concentrations in waters under extreme conditions, but normally the contribution is rather low (approx. $<2 \mu \mathrm{g} \mathrm{L}^{-1}$ ). Higher concentrations in waters are normally associated with geogenic inputs.

- The investigated arable sites showed no significant $U$ accumulation compared to the forest sites. The close correlation of bulk soil AR with $\mathrm{NaHCO}_{3}$-extractable $\mathrm{U}$ indicate that mineral based P-fertilizer application increases the extractable $U$ pool, which might cause higher leachability.

- The lack of depth gradients of $U$ concentrations, $\tau_{\cup}$ and $A R$ ratios are not consistent with accumulation of $U$ in the surface soil, which might indicate leaching of fertilizerderived U. However, based on the calculated $U$ leaching and considering the heterogeneity of the catchment, agricultural practices, and the comparatively long distance to the groundwater, we assume only small contributions (few $\mu \mathrm{g} \mathrm{L}^{-1}$ ) of the fertilizer-derived $U$ to the elevated $U$ concentrations in the water samples.

Based on the estimated contributions of fertilizer-derived $U$ to $U$ in leaching waters, the correlations of $\mathrm{NaHCO}_{3}$-extractable $\mathrm{U}$ and $\mathrm{AR}$, the absence of depth gradients and the $\mathrm{AR}$ in the water samples, it is considered likely that $U$ is leached in the soil. However, while the leaching is in a concentration range that might be relevant at normal $U$ concentrations in drinking water, it is only of minor importance at the high concentrations present in the investigated drinking water wells.

\section{Acknowledgements}

We thank Daniela Fischer and Michael Wendler for their help in the laboratory. We are also grateful to the local authorities and farmers in Walliswil, Oberwil bei Büren and Ins for their support and helpful information. This research did not receive any specific grant from funding agencies in the public, commercial, or not-for-profit sectors. 


\section{Appendix A. Supplementary data}

Supplementary data related to this article can be found online.

\section{References}

Agristat (2013) Statistische Erhebungen und Schätzungen über Landwirtschaft und Erneährung, in: Bauernverband, S. (Ed.), Brugg.

Ahmed, H., Young, S.D. and Shaw, G. (2014) Factors affecting uranium and thorium fractionation and profile distribution in contrasting arable and woodland soils. Journal of Geochemical Exploration 145, 98-105.

Albarède, F. and Beard, B. (2004) Analytical methods for non-traditional isotopes, Reviews in Mineralogy \& Geochemistry, pp. 113-152.

Azouazi, M., Ouahidi, Y., Fakhi, S., Andres, Y., Abbe, J.C. and Benmansour, M. (2001) Natural radioactivity in phosphates, phosphogypsum and natural waters in Morocco. J. Environ. Radioact. 54, 231-242.

Baeza, A., Corbacho, J.A., Guillen, J., Salas, A. and Mora, J.C. (2011) Analysis of the different source terms of natural radionuclides in a river affected by NORM (Naturally Occurring Radioactive Materials) activities. Chemosphere 83, 933-940.

Banning, A., Demmel, T., Rude, T.R. and Wrobel, M. (2013) Groundwater Uranium Origin and Fate Control in a River Valley Aquifer. Environmental Science \& Technology 47, 13941-13948.

Barisic, D., Lulic, S. and Miletic, P. (1992) Radium and Uranium in Phosphate Fertilizers and Their Impact on the Radioactivity of Waters. Water Res 26, 607-611.

Beier, C., Turner, S., Plank, T. and White, W. (2010a) A preliminary assessment of the symmetry of source composition and melting dynamics across the Azores plume. Geochemistry Geophysics Geosystems 11.

Beier, C., Turner, S.P., Sinton, J.M. and Gill, J.B. (2010b) Influence of subducted components on backarc melting dynamics in the Manus Basin. Geochemistry Geophysics Geosystems 11.

Bigalke, M., Ulrich, A., Rehmus, A. and Keller, A. (2017) Accumulation of cadmium and uranium in arable soils in Switzerland. Environ Pollut 221, 85-93.

Birke, M. and Rauch, U. (2008) Uranium in stream water of Germany, in: De Kok, L.J., Schnug, E. (Eds.), Loads and fate of fertilizer derived uranium. Backhuys publishers, Leiden, pp. 79-90. BLW (2014) Agrarbericht, in: Landwirtschaft, B.f. (Ed.), Bern.

Bourdon, B., Turner, S., Henderson, G.M. and Lundstrom, C.C. (2003) Introduction to U-series geochemistry. Rev Mineral Geochem 52, 1-21. 
Brimhall, G.H., Chadwick, O.A., Lewis, C.J., Compston, W., Williams, I.S., Danti, K.J., Dietrich, W.E., Power, M.E., Hendricks, D. and Bratt, J. (1992) Deformational Mass-Transport and Invasive Processes in Soil Evolution. Science 255, 695-702.

CCME (2011) Scientific Criteria Document for the Development of the Canadian Water Quality Guidelines for the Protection of Aquatic Life: Uranium. Canadian Council of Ministers of the Environment, Winnipeg.

Conceicao, F.T. and Bonotto, D.M. (2003) Use of U-isotope disequilibrium to evaluate the weathering rate and fertilizer-derived uranium in Sao Paulo state, Brazil. Environ. Geol. 44, 408-418.

Echevarria, G., Sheppard, M.I. and Morel, J. (2001) Effect of pH on the sorption of uranium in soils. J. Environ. Radioact. 53, 257-264.

FAO (2006) Guidlines for soil description. Food and Agriculture Organization of the United Nations, Rome.

Fuhrer, J., (2014) Wasser in der Landwirtschaft - heute und künftig. Aqua via, 1, 8-11.

Gafvert, T., Holm, E. and Roos, P. (2001) Radionuclide fluxes at a plant manufacturing dicalcium phosphate for domestic animals. J. Environ. Radioact. 54, 61-73.

Grinberg, P., Willie, S. and Sturgeon, R.E. (2005) Determination of thorium and uranium in ultrapure lead by inductively coupled plasma mass spectrometry. Anal. Chem. 77, 2432-2436.

GRUDAF (2009) Grundlagen für die Düngung im Acker- und Futterbau, in: Agroscope (Ed.), Zürich Reckenholz.

Guimond, R.J. and Windham, S.T. (1975) Radioactivity distribution in phosphate products, byproducts, effluents and wastes, Washington, D.C.

Hamamo, H., Landsberger, S., Harbottle, G. and Panno, S. (1995) Studies of Radioactivity and HeavyMetals in Phosphate Fertilizer. J Radioan Nucl Ch Ar 194, 331-336.

Huhle, B., Kummer, S., Stadler, S. and Merkel, B.J. (2008) Mobility of uranium from phosphate fertilizers in sandy soils, in: De Kok, L.J., Schnug, E. (Eds.), Loads and fate of fertilizer derived uranium. Backhuys Publishers, Leiden pp. 47-55.

Jacques, D., Simunek, J., Mallantsl, D. and Van Genuchten, M.T. (2006) Modelling uranium leaching from agricultural soils to groundwater as a criterion for comparison with complementary safety indicators. Mater Res Soc Symp P 932, 1057-1064.

Jones, R.L. (1992) Uranium and Phosphorus Contents in Morrow Plot Soils over 82 Years. Commun. Soil Sci. Plant Anal. 23, 67-73.

Keech, A.R., West, A.J., Pett-Ridge, J.C. and Henderson, G.M. (2013) Evaluating U-series tools for weathering rate and duration on a soil sequence of known ages. Earth and Planetary Science Letters 374, 24-35. 
Keith, S.L., Faroon, O.M. and Fowler, B.A. (2007) Uranium, in: Nordberg, G.F., Fowler, B.A., Nordberg, M. (Eds.), Handbook on the Toxicology of Metals. Academic Press Inc., London, pp. 881-903.

Knolle, F. (2008) Ein Beitrag zu Vorkommen und Herkunft von Uran in deutschen Mineral- und Leitungswässern. PhD thesis, Technische Universität Carolo-Wilhelmia zu Braunschweig, Braunschweig.

Kratz, S., Knappe, F., Rogasik, J. and Schnugg, E. (2008) Uranium balances in agroecosystems, in: de Kok, L.J.a.S., E. (Ed.), Loads and fate of fertilizer derived uranium. Backhuys Publishers, Leiden.

Makweba, M.M. and Holm, E. (1993) The Natural Radioactivity of the Rock Phosphates, Phosphatic Products and Their Environmental Implications. Sci. Total Environ. 133, 99-110.

Mangini, A., Sonntag, C., Bertsch, G. and Muller, E. (1979) Evidence for a Higher Natural Uranium Content in World Rivers. Nature 278, 337-339.

McLaughlin, M.J., Tiller, K.G., Naidu, R. and Stevens, D.P. (1996) Review: The behaviour and environmental impact of contaminants in fertilizers. Aust. J. Soil Res. 34, 1-54.

Mortvedt, J.J. (1994) Plant and Soil Relationships of Uranium and Thorium Decay Series Radionuclides - a Review. J Environ Qual 23, 643-650.

Osmond, J.K. and Cowart, J.B. (1976) The theory and uses of natural uranium isotopic variations in hydrology. Atomic Energy Review 14, 621-679.

Popit, A., Vaupotic, J. and Kukar, N. (2004) Systematic radium survey in spring waters of Slovenia. J. Environ. Radioact. 76, 337-347.

Read, D., Black, S., Beddow, H., Trueman, E. and Baumann, N. (2008) The fate of uranium in phosphate-rich soils, in: De Kok, L.J., Schnug, E. (Eds.), Loads and Fate of Fertilizer Derived Uranium. Backhuys Publishers, Leiden, pp. 65-71.

Regenspurg, S., Margot-Roquier, C., Harfouche, M., Froidevaux, P., Steinmann, P., Junier, P. and Bernier-Latmani, R. (2010) Speciation of naturally-accumulated uranium in an organic-rich soil of an alpine region (Switzerland). Geochimica Et Cosmochimica Acta 74, 2082-2098.

Rogasik, J., Kratz, S., Funder, U., Panten, K., Baumecker, M., Gutser, R. and Lausen, P. (2008) Uranium in soils of German long-term fertilizer experiments, in: De Kok, L.J.S., E (Ed.), Loads and Fate of Fertilizer Derived Uranium. Backhuys Publishers, Leiden, pp. 135-146.

Rothbaum, H.P., Mcgaveston, D.A., Wall, T., Johnston, A.E. and Mattingly, G.E.G. (1979) Uranium Accumulation in Soils from Long-Continued Applications of Super-Phosphate. J. Soil Sci. 30, 147-153.

Sattouf, M. (2007) Identifying the origin of rock phosphates and phosphorous fertilisers using isotope ratio techniques and heavy metal patterns, in: Landbauforschung Völkenrode, S. (Ed.). 
Saueia, C.H.R. and Mazzilli, B.P. (2006) Distribution of natural radionuclides in the production and use of phosphate fertilizers in Brazil. J. Environ. Radioact. 89, 229-239.

Schäf, M., Daumann, L. and Erdinger, L. (2007) Uran in Trinkwasserproben im Rhein-Neckar Gebiet. Universitätsklinikum Heidelberg, Heidelberg.

Schipper, L.A., Sparling, G.P., Fisk, L.M., Dodd, M.B., Power, I.L. and Littler, R.A. (2011) Rates of accumulation of cadmium and uranium in a New Zealand hill farm soil as a result of longterm use of phosphate fertilizer. Agriculture Ecosystems \& Environment 144, 95-101.

Schnug, E. (2012) Uran in Phosphor-Düngemitteln und dessen Verbleib in der Umwelt. Strahlentelex 612-613, 3-7.

Schnug, E. and Lottermoser, B.G. (2013) Fertilizer-Derived Uranium and its Threat to Human Health. Environmental Science \& Technology 47, 2433-2434.

Schott, B. and Wiegand, J. (2003) Processes of radionuclide enrichment in sediments and ground waters of Mont Vully (Canton Fribourg, Switzerland). Eclogae Geol Helv 96, 99-107.

Schulz, C., Rapp, T., Conrad, A., Hünken, A., Seiffert, I., Becker, K., Seiwert, M. and Kolossa-Gehring, M. (2003) Trinkwasser. Elementgehalte im häuslichen Trinkwasser aus Haushalten mit Kindern in Deutschland. Kinder-Umwelt-Survey 2003/06 - KUS.. WaBoLu Hefte 04/08. .

Smidt, G.A., Hassoun, R., Erdinger, L., Schäf, M., Knolle, F. and Utermann, J. (2012) Uranium in German tap and groundwater - Occurence and origins, in: Merkel, B.J., Schipper, M. (Eds.), The New Uranium Mining Boom - Challenge and Lesson learned. Springer, Berlin, Heidelberg.

Stalder, E., Blanc, A., Haldimann, M. and Dudler, V. (2012) Occurrence of uranium in Swiss drinking water. Chemosphere 86, 672-679.

Takeda, A., Tsukada, H., Nanzyo, M., Takaku, Y., Uemura, T., Hisamatsu, S. and Inaba, H. (2005) Effect of long-term fertilizer application on the concentration and solubility of major and trace elements in a cultivated andisol. Soil Sci. Plant Nutr. 51, 251-260.

Takeda, A., Tsukada, H., Takaku, Y., Hisamatsu, S. and Nanzyo, M. (2006) Accumulation of uranium derived from long-term fertilizer applications in a cultivated Andisol. Sci. Total Environ. 367, 924-931.

Taylor, M.D. (2007) Accumulation of uranium in soils from impurities in phosphate fertilisers. Landbauforsch Volk 57 133-139.

Tyler, G., Olsson, T. (2001) Plant uptake of major and minor mineral elements as influenced by soil acidity and liming. Plant Soil 230, 301-321.

Uterman, J. and Fuchs, M. (2008) Uranium in German soils. , in: De Kok, L.J.S., E. (Ed.), Loads and Fate of Fertilizer Derived Uranium. Backhuys Publishers, Leiden, pp. 33-55. 
Vandenhove, H., Van Hees, M., Wouters, K. and Wannijn, J. (2007) Can we predict uranium bioavailability based on soil parameters? Part 1: Effect of soil parameters on soil solution uranium concentration. Environ Pollut 145, 587-595.

Von Gunten, U. (2000) Grundwasser: Vom Trinkwasser-Reservoir zum Gewässer. EAWAG News 49, 35.

Wetterlind, J., Richer De Forges, A.C., Nicoullaud, B. and Arrouays, D. (2012) Changes in uranium and thorium contents in topsoil after long-term phosphorus fertilizer application. Soil Use Manage 28, 101-107.

Weyer, S., Anbar, A.D., Gerdes, A., Gordon, G.W., Algeo, T.J. and Boyle, E.A. (2008) Natural fractionation of U-238/U-235. Geochimica Et Cosmochimica Acta 72, 345-359.

Yamaguchi, N., Kawasaki, A. and liyama, I. (2009) What soil constituents contribute to the accumulation of fertilizer-derived U. Sci. Total Environ. 407, 1383-1390.

Zheng, Z.P., Tokunaga, T.K. and Wan, J.M. (2003) Influence of calcium carbonate on U(VI) sorption to soils. Environmental Science \& Technology 37, 5603-5608.

Zielinski, R.A., Asherbolinder, S. and Meier, A.L. (1995) Uraniferous Waters of the Arkansas River Valley, Colorado, USA - a Function of Geology and Land-Use. Applied Geochemistry 10, 133144.

Zielinski, R.A., AsherBolinder, S., Meier, A.L., Johnson, C.A. and Szabo, B.J. (1997) Natural or fertilizerderived uranium in irrigation drainage: A case study in southeastern Colorado, USA. Applied Geochemistry 12, 9-21.

Zielinski, R.A., Orem, W.H., Simmons, K.R. and Bohlen, P.J. (2006) Fertilizer-derived uranium and sulfur in rangeland soil and runoff: A case study in central Florida. Water Air and Soil Pollution 176, 163-183.

Zielinski, R.A., Simmons, K.R. and Orem, W.H. (2000) Use of U-234 and U-238 isotopes to identify fertilizer-derived uranium in the Florida Everglades. Applied Geochemistry 15, 369-383. 